\title{
Study of the Maximum Power Point Tracking Method for photovoltaic system
}

\author{
Yali Liu', a, Yaqiu Zhang',b \\ ${ }^{1}$ No. 134 Fenghuang Road, Yuxi, Yunnan, China \\ ${ }^{2}$ No. 134 Fenghuang Road, Yuxi, Yunnan, China \\ aliuyali880619@163.com, byqzh@yxnu.net
}

\begin{abstract}
Keywords: Serial resistance, shunt resistance,Maximum Power Point Tracking, PV System, Performance Comparison.

Abstract. In this paper, the influence of serial resistance Rs and shunt resistance Rsh for PV cells are studied. The series resistance Rs has a great influence on the output characteristics of the PV cells. Therefore, it is particularly important to solve the value of Rs for the model of solar cells. Rsh is very large, in the process of PV modular modeling, the value of Rsh can be neglected. Maximum power point tracking(MPPT) algorithms play an important role in the optimization of the power and the efficiency of a photovoltaic(PV) generation system. According to the contradiction of the classical Perturb and Observe(P\&O) method between the corresponding speed and the tracking accuracy on steady-state, an improved MPPT method has been put forwarded in this paper. According to establishing control model and using MATLAB/Simulink to simulate the main circuit and control system, we made the comparison among P\&O method and improved P\&O method. In particular, this study compares the behaviors of each technique in presence of solar irradiation variations. We have also compared the output power of the system with two MPPT method.
\end{abstract}

\section{Introduction}

The application of photovoltaic (PV) system becomes more and more widely due to its highly reliable and easy to use. The main attraction of the PV system is harmless of the environment when they generate electric power. The decrease in cost and the increase in efficiency of PV arrays play important role for PV systems in the near future. A precise current-voltage(V-I) characteristic of PV cells is necessary to estimate their performance and improve the efficiency of the PV power generation system[1]. The equivalent circuit of the PV cell can be expressed as a photodiode with a large p-n junction and PV arrays. Several types of models exist to simulate the behavior of a PV cell[2], some researchers adopt simplified PV models by neglecting the serial resistance Rs and shunt resistance Rsh to estimate the maximum power point of PV systems[3].

In recent years, many MPPT techniques have been proposed by scholars; examples are Constant Voltage (CV) method, Perturb and Observe (P\&O) method, Incremental Conductance (IC) method, Fuzzy Logic method, etc.. The IC method have a high accuracy requirements of the sensor, so the cost of hardware is higher. The P\&O method has been widely used for its simple control algorithm and less measured parameters. Although the $\mathrm{P} \& \mathrm{O}$ method with an easy control algorithm, but it has great oscillation around MPP which will lead to a certain amount of power loss[4].

In this paper, the attention will be focused on the study of the influence of serial resistance $R_{s}$ and shunt resistance $\mathrm{R}_{\mathrm{sh}}$ for PV cells. Then an improved MPPT method is proposed in this paper. Control model is established by using Matlab/Simulink.

\section{PV panel modeling}

The PV cell is composed by many P-N junction semiconductor, it is possible to directly convert light to electricity. The PV cells equivalent circuit see Fig.1, it is based on a diode, adding two resistors to account for internal losses. Iph is a light-generated photocurrent, Rs is the series resistance which takes into account the ohmic losses of the material, the metallization and the contact metal/semiconductor; Rsh represents resistance leakage current from currents between the top and bottom of the cell, by the board in particular and within the material by irregularities or 
impurities[5-6]. Usually Rsh is very big and Rs is very small. Where, Iph is internal photocurrent of photovoltaic cells and Id is the total diffusion current through the P-N junction.

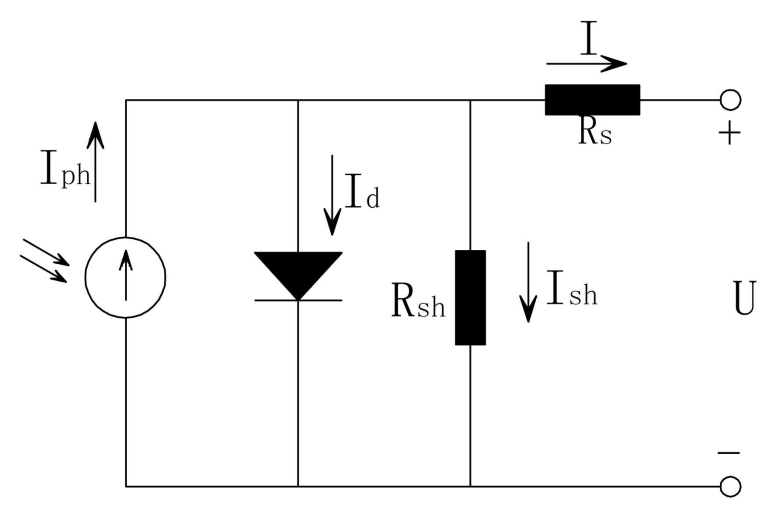

Figure 1. Equivalent circuit of PV cells

From Fig.1, The output current of the cell is given by:

$$
I=I_{p h}-I_{d}-I_{s h}
$$

The light current calculated as follows:

$$
I_{p h}=\left[I_{s c}-K i\left(T-T_{r e f}\right)\right] \frac{S}{1000}
$$

The diode current is defined by Shockley equation:

$$
I_{d}=I_{0}\left[\exp \frac{q\left(U+I R_{s}\right)}{A K T}-1\right]
$$

The current of shunt resistor can be expressed:

$$
I_{s h}=\frac{U+I R_{s}}{R_{s h}}
$$

The mathematical expression of current I for PV cell is given by:

$$
I=I_{p h}-I_{0}\left[\exp \frac{q\left(U+I R_{s}\right)}{A K T}-1\right]-\frac{U+I R_{s}}{R_{s h}}
$$

Where, $\mathrm{q}$ is the electron charge equal to $1.6 \times 10-19 \mathrm{C}, \mathrm{A}$ is the ideality factor of the P-N junction, $\mathrm{K}$ is the Boltzmann constant equal to $1.38 \times 10-23 \mathrm{~J} / \mathrm{K}$.

The current-voltage characteristic of solar cells with different series resistances under constant irradiation intensity is examined. The ideality factor of the diode will be thus taken as $n=1$ in this simulation.

Under the situation of temperature $25^{\circ} \mathrm{C}$, irradiation intensity $1000 \mathrm{~W} / \mathrm{m}^{2}$, the influence of the series resistance Rs for the output characteristics of solar cells under different Rs values ( $\operatorname{Rs}=0,1,2$, and $3 \Omega$ ), are depicted in Fig.2. Fig.2(a) is the I-V curves of the solar cells under different Rs values, Fig.2(b) is the P-V curves of the solar cells under different Rs values. An inspection of Fig.2(a) indicates that the open-circuit voltage ( $\mathrm{Voc}$ ) of the solar cells with different Rs are almost constant at $36.8 \mathrm{~V}$. The corresponding short-circuit currents (Isc) of the solar cells are almost constant at $8.45 \mathrm{~A}$ for $\mathrm{Rs}=0,1,2$, and $3 \Omega$. 


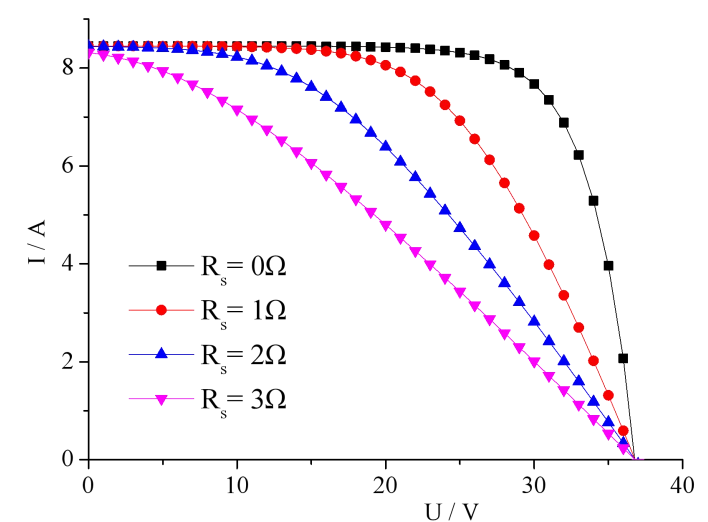

(a)

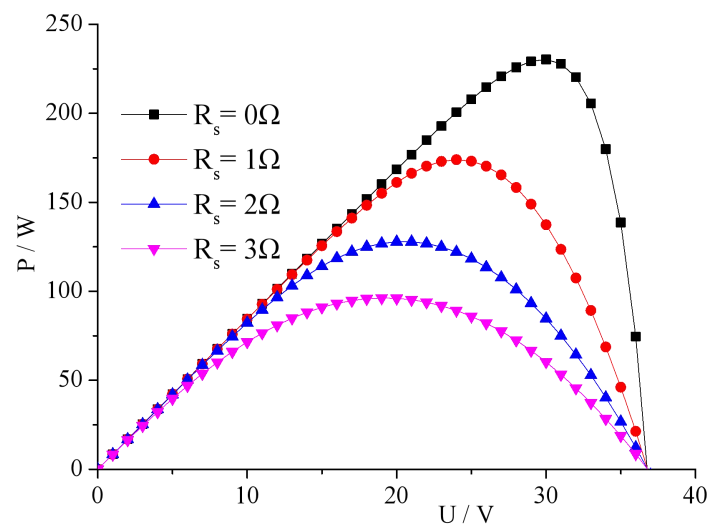

(b)

Figure 2. The influence of the series resistance $R_{s}$ for the output characteristics of solar cells under different $R_{s}$ values $\left(\mathrm{R}_{\mathrm{s}}=0,1,2\right.$,and $\left.3 \Omega\right)$

The maximum power of the solar cells with different Rs values (Rs=0,1, 2, and $3 \Omega$ ) are 230, 173.96, 127.82, and 96.24 W, respectively, as indicated in Fig.2(b). Clearly, the simulation results show that maximum power of the solar cells decrease from $100 \%$ to $41.8 \%$ with an increase in the series resistance Rs from 0 to $3 \Omega$. Thus, the series resistance Rs has a large impact on the output

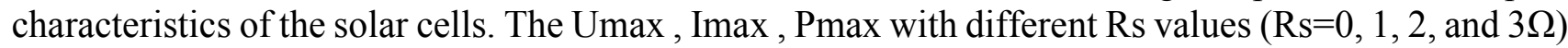
under temperature $25^{\circ} \mathrm{C}$, irradiation intensity $1000 \mathrm{~W} / \mathrm{m} 2$ shows in table 1 . The series resistance Rs has a great influence on the output characteristics of the PV cells. Therefore, it is particularly important to solve the value of Rs for the model of solar cells.

Table 1. The $U_{\max }, I_{\max }, P_{\max }$ with different $R_{s}$ values $\left(R_{s}=0,1,2\right.$, and $\left.3 \Omega\right)$ under temperature $25 \mathrm{C}$, irradiation intensity $1000 \mathrm{~W} / \mathrm{m}^{2}$.

\begin{tabular}{cccc}
\hline $\mathrm{R}_{\mathrm{s}} / \Omega$ & $\mathrm{U}_{\max } / \mathrm{V}$ & $\mathrm{I}_{\max } / \mathrm{A}$ & $\mathrm{P}_{\max } / \mathrm{W}$ \\
\hline $\mathrm{R}_{\mathrm{s}}=0$ & 30 & 7.67 & 230 \\
$\mathrm{R}_{\mathrm{s}}=1$ & 24 & 7.25 & 173.96 \\
$\mathrm{R}_{\mathrm{s}}=2$ & 21 & 6.09 & 127.82 \\
$\mathrm{R}_{\mathrm{s}}=3$ & 19 & 5.07 & 96.24
\end{tabular}

Under the situation of temperature $25 \mathrm{C}$, irradiation intensity $1000 \mathrm{~W} / \mathrm{m} 2$, the influence of Rsh for the output characteristics of solar cells under different Rsh values (Rsh=100, 500, 1000, 1500 and $2000 \Omega$ ) are depicted in Fig. 3.

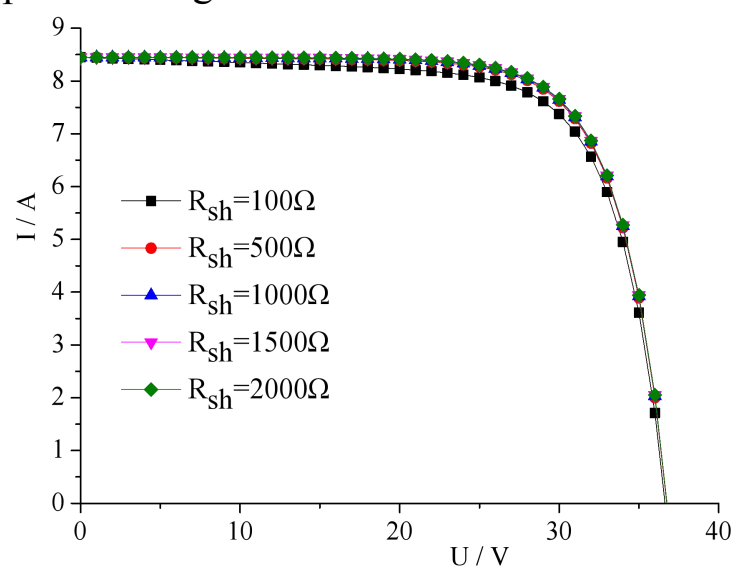

(a)

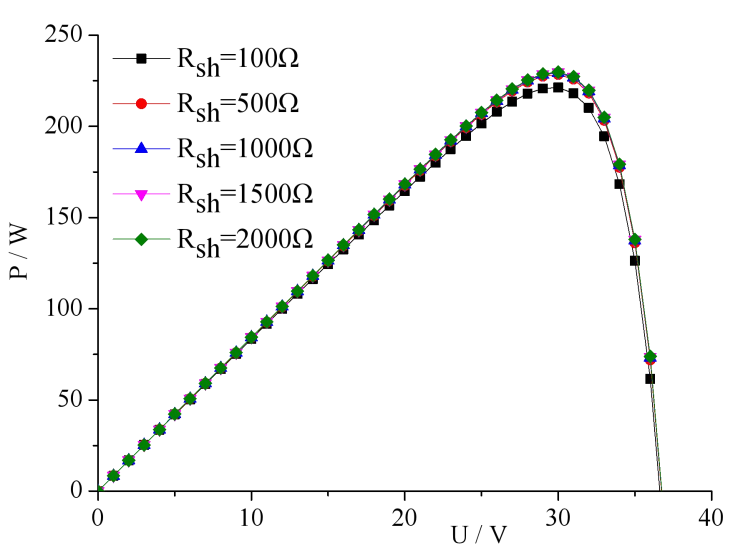

(b)

Figure 3. The influence of the series resistance $\mathrm{R}_{\text {sh }}$ for the output characteristics of solar cells under different $\mathrm{R}_{\text {sh }}$ values $\left(\mathrm{R}_{\text {sh }}=100,500,1000,1500\right.$ and $\left.2000 \Omega\right)$

Fig. 3(a) is the I-V curves of the solar cells under different Rsh values, Fig. 3(b) is the P-V curves of the solar cells under different Rsh values. The simulation results show that the I-V curves and P-V curves of the solar cells almost the same under different Rsh values (Rsh=500, 1000, 1500 and 2000 
$\Omega$ ). Thus, Rsh has little impact on the output characteristics of solar cells when the value of Rsh higher than $500 \Omega$. Effectively, Rsh is very large, in the process of PV modular modeling, the value of Rsh can be neglected.

The effect of shunt resistance Rsh is negligible, the mathematical expression of current I and voltage $\mathrm{U}$ for PV cell can be expressed:

$$
I=I_{p h}-I_{0}\left[\exp \frac{q\left(U+I R_{S}\right)}{A K T}-1\right]
$$

In this paper, the Eq. 6 is used for establishing the simulation model of PV panel. The parameters of PV panel selected in this paper see Table 2.

Table 2 Electrical characteristics of PV panel

\begin{tabular}{ccc}
\hline Symbol & meaning & Value \\
\hline $\mathrm{P}_{\max }$ & Maximum Power & $230 \mathrm{~W}$ \\
$\mathrm{U}_{\mathrm{m}}$ & Voltage at $\mathrm{P}_{\max }$ & $29.5 \mathrm{~V}$ \\
$\mathrm{I}_{\mathrm{m}}$ & Current at $\mathrm{P}_{\max }$ & $7.8 \mathrm{~A}$ \\
$\mathrm{U}_{\mathrm{oc}}$ & Open-Circuit Voltage & $36.8 \mathrm{~V}$ \\
$\mathrm{I}_{\mathrm{sc}}$ & Short-Circuit Current & $8.45 \mathrm{~A}$ \\
\hline
\end{tabular}

\section{MPPT Control Algorithms}

Constant voltage is a method to approximate maximum power point (MPP) by using constant voltage control algorithm[7-8].

When the temperature is constant, the maximum power point of photovoltaic cells under different irradiance distribution on a straight line approximately, that is the maximum power point of pv cells similar at a constant voltage $U_{m}$ [9-11]. The relationship between $U_{m}$ and $U_{o c}$ is given by: $U_{m}=k U_{o c}$

Where, the value of $\mathrm{k}$ is among $0.7 \sim 0.8$.

The basic principle of constant voltage method as follows: sampling the open circuit voltage of a solar cell, then calculating the value of Um according to the formula (7), through the control circuit to make the system output maximum power.

Perturb and Observe Method(P\&O) is widely used due to its quite simple structure and the few measured parameters involved. The basic principle as follows: The $\mathrm{P} \& \mathrm{O}$ algorithms operate by periodically perturbing the array terminal voltage, then observing the changes of the PV output power, comparing the PV output power with that of the previous perturbation cycle, if the power is increased, the perturbation will be in the same direction, otherwise, it will be in the opposite direction, in the next perturbation cycle the algorithm continues in the same way. Finally the PV cells will work at the maximum power point.

This method presents the structure of a simple regulation in closed-loop where only a few controlled parameters are involved. By varying the voltage of the PV panel periodically with a very small incremental step to reduce the oscillation around the MPP, the $\mathrm{P} \& \mathrm{O}$ algorithm compares the power previously delivered with the one after disturbance.

To solve the contradiction of the P\&O method between the tracking accuracy and tracking speed, an improved MPPT method by combination the constant voltage method and perturb and observe method is proposed. We will set the start voltage as $0.78 \mathrm{Uoc}$, and then use the perturb and observe method to tracking the MPP. 


\section{Simulation results and analysis}

Based on the principle of the improved MPPT method mentioned above, we established the simulation model on the basis of Matlab/Simulink. The simulation model shown in Fig.4. The improved MPPT algorithm is realized by S-Function.

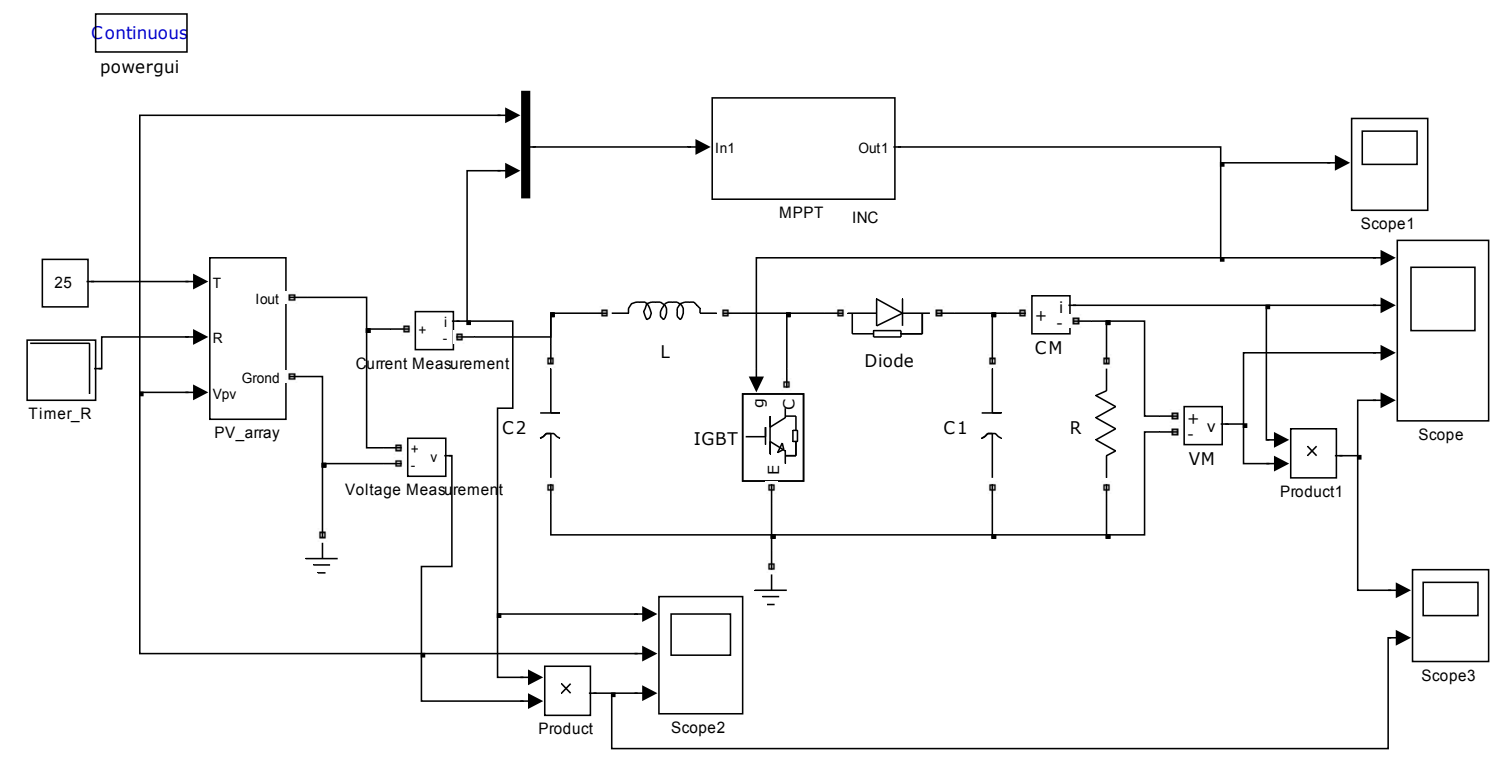

Figure 4. Simulation model of $\mathrm{P} \& \mathrm{Ob}$ method

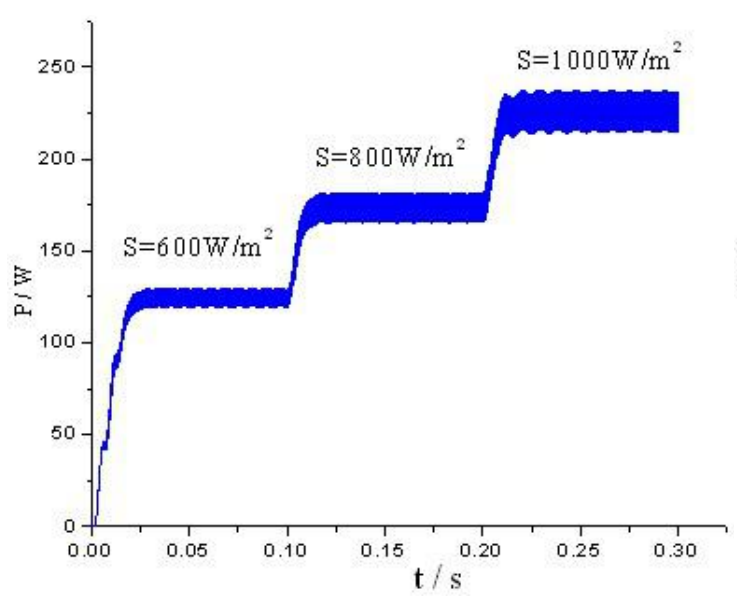

(a)

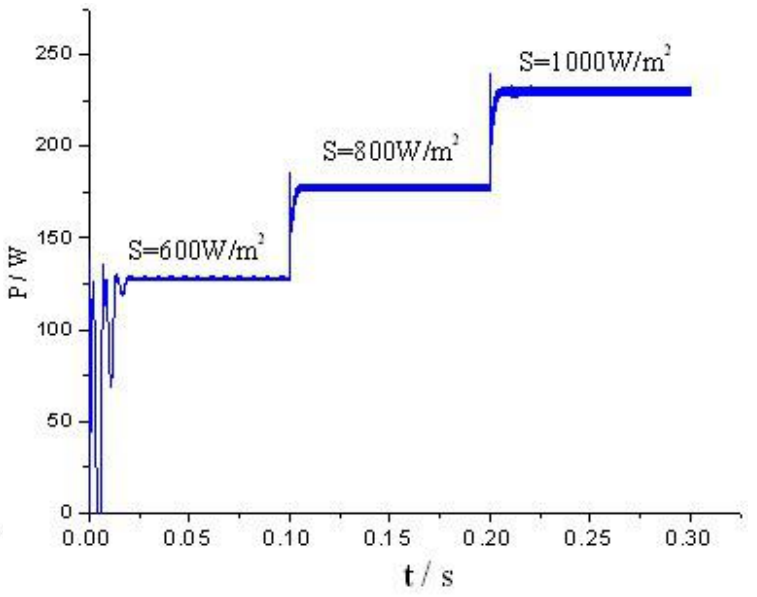

(b)

Figure 5. $\mathrm{T}=25 \mathrm{C}$, the output power of $\mathrm{PV}$ systems for two MPPT methods under different radiation: a) $\mathrm{P} \& \mathrm{O}$ method, b) improved method.

To analyze and compare the performance of the MPPT algorithms presented above,we carried out a simulation study. The temperature is maintained constant $(25 \mathrm{C})$, under different radiation levels $\left(600 \mathrm{~W} / \mathrm{m}^{2}, 800 \mathrm{~W} / \mathrm{m}^{2}\right.$ and $1000 \mathrm{~W} / \mathrm{m}^{2}$. The simulation results as in Fig.5. In these figures,(a) is the power of PV systems by using the P\&O method, (b) is the power of PV systems by using the improved MPPT method. Fig.5(a) shows that it presents strong oscillation when it reaches MPP and the. Fig.5(b) shows that the improved method track in right direction and present weak oscillation at MPP. The improved method presents better efficiency when the radiation changes rapidly and a better stability when the MPP is reached. 


\section{Conclusions}

In this paper, the attention is focused on the study of the influence of serial resistance Rs and shunt resistance Rsh for PV cells. Then an improved MPPT method is proposed in this paper. Control model is established by using Matlab/Simulink. The maximum power of the solar cells with different Rs values (Rs=0,1,2, and $3 \Omega$ ) are 230, 173.96, 127.82, and $96.24 \mathrm{~W}$, respectively, the simulation results show that maximum power of the solar cells decrease from $100 \%$ to $41.8 \%$ with an increase in the series resistance Rs from 0 to $3 \Omega$. Thus, the series resistance Rs has a large impact on the output characteristics of the solar cells. Rsh has little impact on the output characteristics of solar cells when the value of Rsh higher than $500 \Omega$. Effectively, Rsh is very large, in the process of PV modular modeling, the value of Rsh can be neglected.

To solve the contradiction of the P\&O method between the tracking accuracy and tracking speed, an improved MPPT method by combination the constant voltage method and perturb and observe method is proposed. We will set the start voltage as $0.78 \mathrm{Uoc}$, and then use the perturb and observe method to tracking the MPP. The improved method track in right direction, present weak oscillation at MPP and better efficiency when the radiation changes rapidly and a better stability when the MPP is reached compared with $\mathrm{P} \& \mathrm{O}$ method.

\section{Acknowledgements}

This work was financially supported by the Science and Technology Department Youth Projects of Yunnan province, China (Grant No.: 2015FD091).

\section{References}

[1] T.Ikegami, T.Maezono and F.Nakanishi. Estimation of equivalent circuit parameters of PV module and its application to optimal operation of PV system. Solar Energy Materials \& Solar Cells. (2001), p. 389.

[2] M.T.Benmessaoud, F.Z.Zerhouni and M.Zegrar. New approach modeling and a maximum power point tracker method for solar cells. Computers and Mathematics with Applications.(2010), p.1124.

[3] A. Zegaoui,M. Aillerie and P. Petit. Dynamic behaviour of PV generator trackers under irradiation. Solar Energy. (2011), p. 2953.

[4] G. K.Singh. Solar power generation by PV technology. A review Solar Energy. (2013),p.1.

[5] Li Jing, Wei D and Zhengguo X. Research on MPPT Methods of photovoltaic. Acta energiae solaris sinica.(2007), p.268.

[6] Yi-Hua Liu, Jia-Wei. Huang. A fast and low cost analog maximum power point tracking method for low power photovoltaic systems Solar Energy. (2011), p.2771.

[7] Jian C, Zhengming Z. Comparison of maximum power point tracking. J T sing hua Univ ( Sci \& Tech).(2010), p.700.

[8] TANG Qiang, XUE Tai-lin. A Photovoltaic Module Simulation Based on Matlab/Simulink. Telecom Power Technology. (2011 ), p. 38.

[9] A. DOLARA, R. FARANDA and S. LEVA. Energy Comparison of Seven MPPT Techniques for PV Systems . J. Electromagnetic Analysis \& Applications. (2009), p. 152.

[10] Tafticht T, K. Agbossou and Doumbia M. An improved maximum power point tracking method for. Renewable Energy. (2008 ), p. 1508.

[11] A. Zegaoui1, M. Aillerie1 and P. Petit. Comparison of Two Common Maximum Power Point Trackers by Simulating. Energy Procedia. (2011), p.678. 